\title{
Development and Application of Logistics Supply Chain Management Technology
}

\author{
Sun Kai \\ Huanggang Polytechnic College, Hubei, China, 438002
}

Keywords: Logistics; supply chain; management technology

\begin{abstract}
Logistics supply chain management technology is a new management mode which integrates advanced technologies such as logistics management, management information technology, computer technology and network technology. It builds a cooperative platform for consultation and collaboration among enterprises, suppliers and customers. It not only promotes the development of enterprises, but also improves the market competition demand and meets the needs of customers. This management technology can be called "management technology". It is a development technology with higher potential in the new era. Under the development of the new era, logistics supply chain management technology also needs continuous innovation, effective promotion and application to improve the speed of development, and to upgrade the management technology level under the logistics supply chain mode in the new era.
\end{abstract}

With the deepening of the globalization process, enterprises want to have a firm position in the fierce market competition. In addition to improving their soft power, they also need to keep pace with the times and establish a modern enterprise management model. Logistics supply chain is one of them. Therefore, enterprises need to improve the management technology of logistics supply chain, update and develop advanced technology such as logistics management technology, while understanding the problems of their own supply chain, actively seek solutions, so as to enhance the competitiveness of enterprises themselves.

\section{Basic overview of supply chain management}

\subsection{Supply Chain}

Supply chain refers to the flow of funds and information between related departments or business partners. The whole process covers the procurement, design, packaging and payment of raw materials. It is a business process activity.

\subsection{Development of Horizontal Integration in Supply Chain Management}

From another point of view, the definition of supply chain management means that enterprises rely on modern information technology, computer network technology and data communication technology to supervise the whole process of commodity logistics, integrate and protect the 
business information and resources in the supply chain, so as to maximize the quality of logistics transactions, so as to not only meet the needs of customers reasonably, but also meet the needs of customers at the same time. It can also reduce the cost of the supply chain system, which is conducive to improving the social benefits of enterprises.

\section{Existing Problems in Enterprise Logistics Supply Chain}

China's logistics industry starts late, develops slowly, and has a situation of high cost and low benefit. Not only that, because of the different economic development in different regions of China, the development of logistics supply is unbalanced, and the gap between the eastern and Western regions, developed and undeveloped regions is very large. At the same time, the logistics supply situation of different industries is also very different, the logistics supply capacity of retail industry is stronger, while the ability of some chemical industries and agricultural products is weaker. In addition, the logistics supply chains of different types of enterprises are also very different. Large enterprises develop faster, small enterprises develop slower, foreign-funded enterprises develop faster and private enterprises develop slower. As shown in Figure 1.

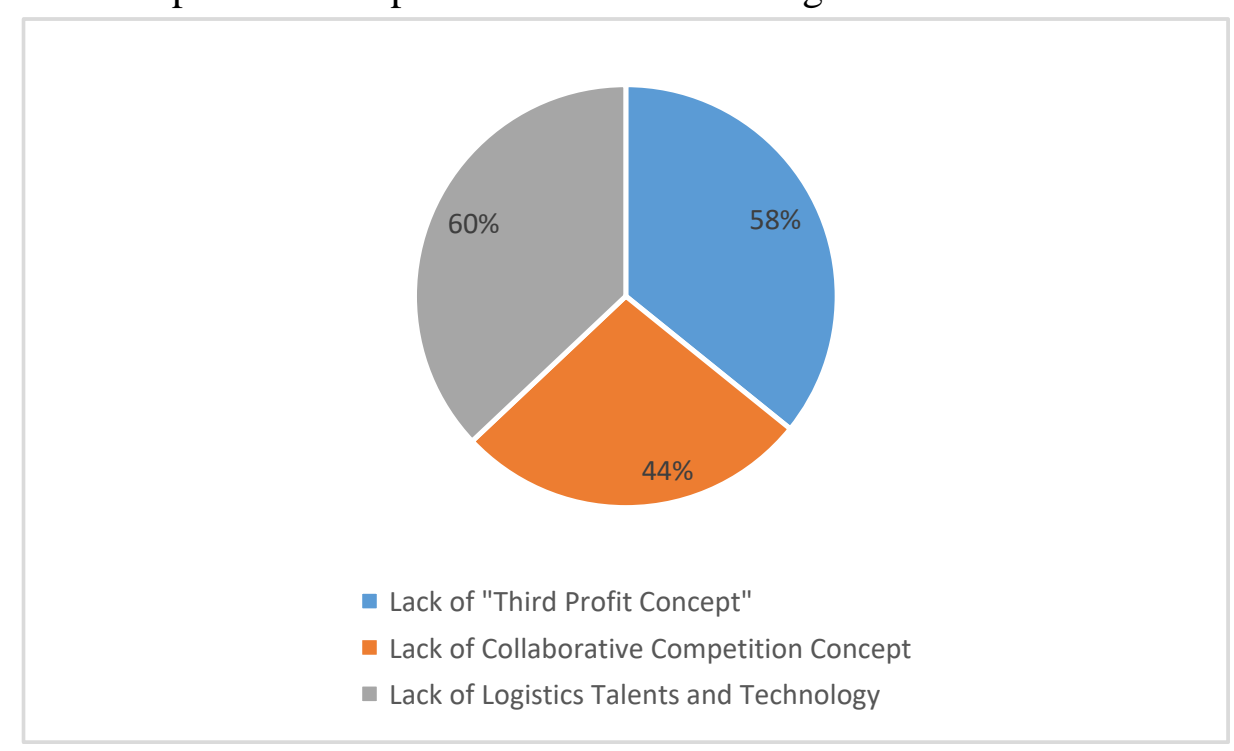

Figure 1. Existing Problems in Enterprise Logistics Supply Chain

\subsection{Lack of "Third Profit Concept"}

As we all know, the link of logistics supply chain can be roughly divided into supply, production and sales. In order to "reduce expenditure and open source" and increase enterprise efficiency, enterprises often save money and costs in the supply and production links, but neglect the saving space in the sales links.

\subsection{Lack of Collaborative Competition Concept}

Under the pressure of fierce market competition and changing consumption demand, it is imperative to establish logistics chain of enterprises. However, there are still a few cases of logistics chain cooperation among enterprises in our country. Most of them are still at their own stage. There are too few exchanges between enterprises and lack of the concept of cooperation to meet opportunities and challenges. They can not integrate all links of logistics supply chain organically and achieve win-win situation among enterprises. 


\subsection{Lack of Logistics Talents and Technology}

Because of the late start of the logistics industry in China, it is difficult for the education of logistics talents to keep up with the market demand. Now the enterprises that have established the internal logistics supply chain of enterprises are also very short of professional logistics personnel, specializing in the management of transportation, custody, handling, transfer and other work. In addition, domestic logistics standardization is very low, the scope of application standards is limited, and the implementation is not enough, there are many details.

\section{Effective Application Strategy of Logistics Supply Chain Management Technology}

Through the analysis of the innovation points of logistics supply chain management technology development, we can see that if enterprises want to use logistics management technology to obtain higher economic benefits and improve their competitiveness, they need to establish an interactive system, set up the application core of logistics management technology, coordinate enterprise relations and achieve the goal of information sharing. Therefore, all enterprises in the supply chain need to keep pace with the times. God, actively apply innovative supply chain management technology, with the support of advanced science and technology, improve the quality of logistics supply chain management. As shown in Figure 2.

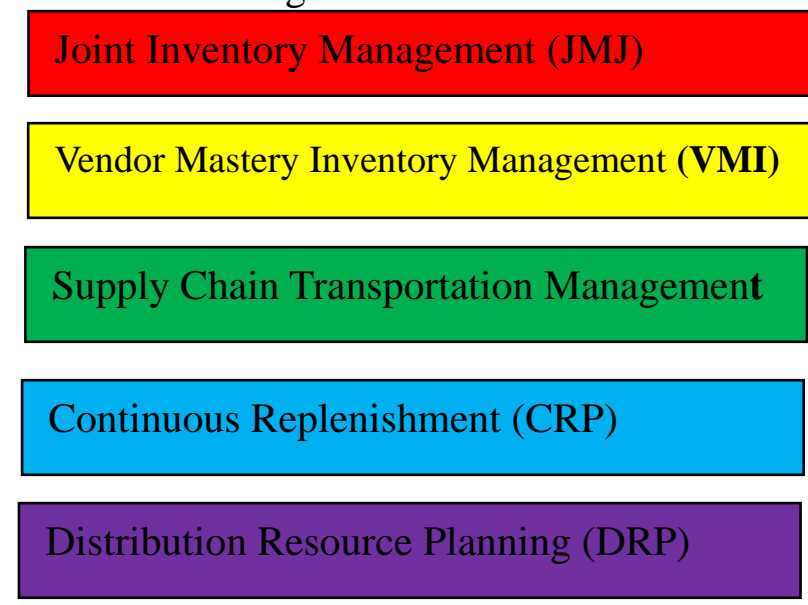

Figure 2. Effective Application Strategy of Logistics Supply Chain Management Technology

\subsection{Joint Inventory Management (JMJ)}

Joint inventory management mainly centers on the core of logistics supply chain. Based on the designated core of logistics supply chain management within each enterprise or enterprise, the inventory management system is formulated. The basis of reasonable distribution and control of inventory management is laid out in the enterprise, and the joint inventory control system is established to achieve the management objectives of real-time supervision and flexible allocation of inventory information.

\subsection{Vendor Mastery Inventory Management (VMI)}

VMI is a new inventory management technology. Based on summarizing the experience of logistics supply chain management, it clarifies the actual demand of suppliers for inventory information. For this reason, it formulates a supplier inventory management system around this demand, enriches the inventory management system, and then subverts the management form of 
core enterprises purchasing materials from suppliers, and self-management, consumption and self-financing of profits and losses, so as to avoid emergence from the source. The abnormal backlog of raw material acquisition highlights the application value of innovative technology in logistics supply chain management.

\subsection{Supply Chain Transportation Management}

At the same time of reasonable inventory management, logistics supply chain needs to make good transportation management to improve the speed and safety of logistics transportation. Therefore, enterprises need to formulate scientific and reasonable transportation plan according to the transport demand of the core management object, and complete the transportation task through logistics management. For example, while producing a certain kind of products in batches, enterprises in charge of the transportation link need to determine the transportation route beforehand, master the storage and transportation conditions of such products, build a good product transportation environment, avoid the loss and deterioration of products in the process of transportation, and improve the transportation organization and management and control ability.

\subsection{Continuous Replenishment (CRP)}

In order to promote the development of logistics supply chain management system towards intensive direction, on the basis of sharing and developing innovation of management technology and information, a continuous supplementary cargo management mechanism is formed, in which the producers and distributors are mainly involved. By analyzing product sales information, the producers formulate production plans rationally, and supply products to distributors in batches and small batches, so as to make sales section.

\subsection{Distribution Resource Planning (DRP)}

DRP is mainly responsible for solving the distribution material dispatching problem in the logistics supply chain, making it meet the operational needs of all enterprises, so that the resources in the supply chain can be allocated reasonably, managed scientifically, dealt with the distribution materials reasonably, and saved the cost of resource allocation. By using this technology, the efficiency of logistics supply chain management can be improved.

\section{Conclusion}

In summary, the development and innovation of logistics supply chain management technology has never stagnated. With the accumulation of logistics management experience in China and the research and application of Internet and advanced management technology, people will innovator develop this management technology around establishing a system, clarifying the core of logistics supply chain, coordinating enterprise relations, information sharing, and continuously replenishing existing goods and joint inventory management. On the basis of management technology, such as distribution resource planning, we should expand the integration of advanced technology and logistics supply chain management, then create higher economic benefits for enterprises, and help the steady development of our market economy.

\section{References}

[1] Chang An. Innovation and Application of Logistics Supply Chain Management Technology [J]. China Commerce, 2018 (17). 
[2] Wang Fandango. Logistics Management Strategy Research Based on Supply Chain Management Environment [J]. Value Engineering, 2018 (10).

[3] Bhang Xiaoping, Li Furlong. Study on Logistics Model of Small and Medium-sized Tea Enterprises Based on Supply Chain Management [J]. Fijian Tea, 2018 (6).

[4] Li Tijuana. Cost Management of Enterprise Logistics from the Perspective of Supply Chain [J]. China Business, 2018 (12).

[5] Bu Zhukov, An Song, Duo Ian, ET AL. Logistics risk transmission mechanism and control of fresh agricultural products supply chain [J]. Journal of Southwest Tongan University, 2018 (3). 